\title{
Task Delegation and Burnout Trade-offs Among Primary Care Providers and Nurses in Veterans Affairs Patient Aligned Care Teams (VA PACTs)
}

\author{
Samuel T. Edwards, MD, MPH, Christian D. Helfrich, MPH, PhD, \\ David Grembowski, PhD, Elizabeth Hulen, MA, Walter L. Clinton, PhD, \\ Gordon B. Wood, MS, Linda Kim, PhD, MSN, RN, PHN, Danielle E. Rose, PhD, \\ and Greg Stewart, $\mathrm{PhD}$
}

Purpose: Appropriate delegation of clinical tasks from primary care providers (PCPs) to other team members may reduce employee burnout in primary care. However, (1) the extent to which delegation occurs within multidisciplinary teams, (2) factors associated with greater delegation, and (3) whether delegation is associated with burnout are all unknown.

Methods: We performed a national cross-sectional survey of Veterans Affairs (VA) PCP-nurse dyads in Department of VA primary care clinics, 4 years into the VA's patient-centered medical home initiative. PCPs reported the extent to which they relied on other team members to complete 15 common primary care tasks; paired nurses reported how much they were relied on to complete the same tasks. A composite score of task delegation/reliance was developed by taking the average of the responses to the 15 questions. We performed multivariable regression to explore predictors of task delegation and burnout.

Results: Among 777 PCP-nurse dyads, PCPs reported delegating tasks less than nurses reported being relied on (PCP mean \pm standard deviation composite delegation score, 2.97 \pm 0.64 [range, 1-4]; nurse composite reliance score, $3.26 \pm 0.50$ [range, 1-4]). Approximately 48\% of PCPs and 35\% of nurses reported burnout. PCPs who reported more task delegation reported less burnout (odds ratio [OR], 0.62 per unit of delegation; 95\% confidence interval [CI], 0.49-0.78), whereas nurses who reported being relied on more reported more burnout (OR, 1.83 per unit of reliance; $95 \%$ CI, $1.33-2.5)$.

Conclusions: Task delegation was associated with less burnout for PCPs, whereas task reliance was associated with greater burnout for nurses. Strategies to improve work life in primary care by increasing PCP task delegation must consider the impact on nurses. (J Am Board Fam Med 2018;31:83-93.)

Keywords: Cross-sectional Studies, Patient Care Team, Patient-Centered Care, Personnel Turnover, Primary Health Care, Professional Burnout, Veterans

Primary care involves an array of tasks including gathering patient history, screening, evaluation, intervention, health education, care coordination, and communication with patients outside of face-

\footnotetext{
This article was externally peer reviewed.

Submitted 28 February 2017; revised 2 September 2017; accepted 10 September 2017.

From the Section of General Internal Medicine and the Center to Improve Veteran Involvement in Care, VA Portland Health Care System, Portland, OR (STE, EH); the Division of General Internal Medicine and Geriatrics and the Department of Family Medicine (STE), Oregon Health \& Science University, Portland; the Seattle-Denver Center of Innovation for Veteran-Centered and Value-Driven Care, US Department of Veterans Affairs, Seattle,
}

to-face visits. ${ }^{1-4}$ An underlying objective of teambased care models such as the patient-centered medical home $(\mathrm{PCMH})$ is the development of an

WA (CDH, WLC, GBW); the Department of Health Services, University of Washington School of Public Health, Seattle (CDH, DG); the VA HSR\&D Center for Study of Healthcare Innovation, Implementation \& Policy, Greater Los Angeles Health Care System, Los Angeles, CA (LK, DER); the VISN 23 Patient Aligned Care Team Demonstration Laboratory, Iowa City VA Health Care System, Iowa City, IA (GS); and the Department of Management, University of Iowa, Iowa City (GS).

Funding: This work was supported by the Patient Centered Medical Home Demonstration Laboratory Coordination Center (XVA-61-041) of the U.S. Department of Veterans Affairs. 
interdisciplinary team that shares primary care tasks and allows members to work at the top of their competence. ${ }^{5,6}$ However, differences in power and status, as well as a lack of clarity about who should do what, makes delegating tasks a challenge. ${ }^{7-9}$ Teams struggle with poor role clarity and confusion over responsibility for clinical tasks. ${ }^{10-15}$

Team struggles over who should do which tasks may contribute to work-related burnout, a psychological state characterized by emotional exhaustion, lack of enthusiasm, and feelings of ineffectiveness. ${ }^{16,17}$ Burnout is common among primary care providers $(\mathrm{PCPs})^{18,19}$ and primary care nurses ${ }^{20}$, with potentially negative implications for patient satisfaction $^{21,22}$, patient safety ${ }^{18,23,24}$, and employee turnover. ${ }^{25}$ Clinical workload, unstable and inadequate staffing ${ }^{26}$, and performing tasks that do not take advantage of a team members' skills ${ }^{27}$ are associated with increased burnout. By contrast, perception that a team culture exists is greater ${ }^{28}$ and more sharing of clinical and clerical tasks ${ }^{29}$, are associated with lower burnout among PCPs and staff. Improving task delegation among interdisciplinary team members in a PCMH model may thus reduce burnout among PCPs and staff.

In 2010, the US Department of Veterans Affairs (VA) began implementing its PCMH model through the Patient Aligned Care Teams (PACT) initiative in VA primary care clinics. Within the VA PACT model, a "teamlet" consists of 4 members: a PCP (physician, nurse practitioner, physician assistant), nurse care manager (registered nurse), clinical associate (licensed practical nurse/licensed vocational nurse), and administrative associate (medical assis$\operatorname{tant).~While~guidelines~were~distributed~describing~}$ the role of each team member ${ }^{30}$, teams were given substantial flexibility in determining their own workflows. Early in the implementation of PACT, significant differences existed between PCP's and nurses' perceptions of responsibility for specific clinical tasks: PCPs reported they perform most clinical tasks alone, whereas nurses reported they were relied on for the same tasks. ${ }^{11}$ However, these discrepant findings may have occurred because PCPs and nurses were sur-

Conflict of interest: none declared.

Corresponding author: Samuel T. Edwards, MD, MPH, Section of General Internal Medicine, VA Portland Health Care System, 3710 SW US Veterans Hospital Rd. (R\&D199), Portland, OR 97239 (E-mail: samuel.edwards@ va.gov). veyed separately, rather than analyzing responses from PCPs and nurses in the same team. In addition, it remains unknown how perceived task delegation relates to employee burnout.

In this study we surveyed PCPs and nurses 4 years into PACT implementation to examine whether PCP and nurse perceptions of task delegation were similar or different within matched PCP-nurse dyads (ie, PCPs and nurses in the same teamlet). We examined factors that might contribute to perceptions of task delegation and whether task delegation was associated with employee burnout.

\section{Methods}

Our study is part of the national PACT Demonstration Laboratory Initiative efforts to support and evaluate the VA's transition to the PCMH model. This study is based on the 2014 national provider and staff survey, which was designed to assess primary care personnel's perceptions of work conditions during PACT implementation.

The survey was reviewed by national union leaders through VA Labor Management Relations to ensure that surveys were not coercive or a danger to employees. The study was considered a quality improvement project by VA national primary care leadership and was exempt from institutional review board review.

\section{Procedures and Participants}

The survey was administered online from August 4 through September 1, 2014, using Inquisit software (Millisecond Software, Seattle, WA). A survey link was sent via E-mail to national VA primary care leadership, who disseminated it to leaders of the regional networks and local facilities with a request for them to distribute the link to local primary care personnel. Three E-mail reminders were sent, and no incentives were used. The survey asked respondents to self-identify using a nationally designated primary care team identifier; the completed surveys did not include individual identifiers. Because the survey was disseminated electronically through leadership channels, we do not know the exact number of eligible employees who were contacted; that is, we do not have a true denominator with which to calculate a response rate. We estimated the individual response rate to be $21 \%$ based on the number of providers (physicians, nurse practitio- 


\begin{tabular}{lc}
\hline Task & Task Groupings \\
\hline Gathering patient preventive services history (eg, immunization history) & In-person data collection \\
Screening patients for diseases (eg, doing a depression screen) & Messaging \\
Assessing patient lifestyle factors (eg, diet, smoking cessation) & Counseling/education \\
Receiving messages from patients (other than requests for prescriptions) & Decision making \\
Resolving messages from patients (other than requests for prescriptions) & Responding to prescription refill requests \\
Encouraging lifestyle modifications (eg, diet, smoking cessation) & Tracking data \\
Educating patients about disease-specific self-care activities (eg, foot care in diabetes) & \\
Evaluating patients and making treatment decisions & \\
Completing forms for patients (eg, disability documentation) & \\
Responding to requests for home health care orders & \\
Responding to patient diagnostic and treatment data (eg, laboratory tests, radiology studies) & \\
\hline Following up on referrals (eg, to specialists) &
\end{tabular}

ners, and physician assistants) who responded relative to the number of providers in a panel management database during the same period, which was the most reliable administrative data on personnel nationally. Administrative records indicated that 8114 primary care teamlets existed in the VA at the time of our survey; 2809 teamlets had at least 1 respondent and $20.9 \%$ of active PCPs returned surveys. Our sample consisted of 721 PCPs and 598 nurses, who together compromised 777 PCP-nurse dyads in 554 teamlets.

\section{Study Measures}

\section{Employee Perceptions of Task Delegation/Reliance and Discordance}

We asked PCPs and nurses about how 15 common primary care tasks (Table 1) were performed. We asked PCPs, "To what extent do you rely on your teamlet to accomplish the following primary care activities?" We asked nurses, "To what extent does your teamlet/clinic team rely on you to accomplish the following primary care activities?" PCPs and nurses responded on a 4-point scale for each task: "not at all" (1), "slightly" (2), "somewhat" (3), or "a great deal" (4). We defined these measures as "task delegation" for PCPs and "task reliance" for nurses. We calculated the absolute value of the difference between PCP task reliance and nurse task reliance for each dyad; this was defined as "task discordance." Two clinician researchers grouped the 15 tasks into 5 categories based on exploratory factor analysis and clinical experience. The task questions were developed by clinicians and social scientists with experiencing practicing and studying primary care at the VA, and the questions have been used in several published studies. ${ }^{11,31,32}$

\section{Composite Task Delegation/Reliance Score}

To generate a composite task delegation/reliance score, we calculated the mean of the scores for all respondents across all 15 tasks. We also calculated the mean task delegation/reliance score for each task and task grouping.

\section{Burnout}

Burnout was measured by a single item, a 5 -point measure used in the Physician Worklife Study and several other large studies of burnout among physicians in the United States. ${ }^{33,34}$ The specific question is, "Overall, based on your definition of burnout, how would you rate your level of burnout?" Responses were scored on a 5-category ordinal scale: 1 = "I enjoy my work. I have no symptoms of burnout"; 2 = "Occasionally I am under stress, and I do not always have as much energy as I once did, but I do not feel burned out"; 3 = "I am definitely burning out and have 1 or more symptoms of burnout, such as physical and emotional exhaustion"; 4 = "The symptoms of burnout that I am experiencing will not go away. I think about frustration at work a lot"; and 5 = "I feel completely burned out and often wonder if I can go on. I am at the point where I may need some changes or may need to seek some sort of help." This question has been validated previously against the Emotional Exhaustion Subscale of the Maslach Burnout Inven- 
tory. ${ }^{26,33,35}$ Consistent with previous analyses, a score $\geq 3$ was considered burnout. ${ }^{31}$

\section{Staffing, Coaching, Huddles, and Tenure at the VA}

Other independent variables from the survey included perception of adequate staffing ("Is your PACT staffed at the recommended 3 FTE [fulltime equivalent] team members to each PCP FTE?" [yes $=1 /$ no $=0]$ ), perception of recent staff turnover ("Has your teamlet had any changes in or loss of staff in the past 12 months?" [yes $=1 /$ no $=$ 0]), minutes spent in huddles ("Thinking about a typical day in your primary care clinic, about how much time do you spend on meeting with your teamlet/clinic to discuss patient care [eg, in huddles]?" [do not huddle (coded as 0 minutes), $\leq 5$ minutes (coded as 2.5 minutes), 6 to 10 minutes (coded as 8 minutes), 11 to 20 minutes (coded as 15.5 minutes), 21 to 30 minutes (coded as 25.5 minutes), $>30$ minutes (coded as 30 minutes)]), presence of a PACT coach ("Did your PACT have a coach?" [yes $=1 /$ no $=0]$ ), and duration of VA employment ("How long have you worked for the Veterans Health Administration?" [ $<6$ months (coded as 3 months), 6 months to 1 year (coded as 9 months), 1 to 2 years (coded as 18 months), 2 to 5 years (coded as 42 months), 5 to 10 years (coded as 90 months), 10 to 15 years (coded as 150 months), 15 to 20 years (coded as 210 months), $>20$ years (coded as 240 months)]).

\section{Statistical Analysis}

We reviewed summary statistics to describe characteristics of the sample and to compare task delegation/reliance and burnout in PCPs and nurses. Because the composite task delegation/reliance score had a range of noninteger values, we used it as a continuous variable in regression models. We performed linear regression to test the association between independent variables and composite task delegation/reliance. We performed multivariable logistic regression to explore associations with burnout at the respondent level. Because some dyads came from the same teamlets (ie, some nurses worked with $>1$ PCP), we used GLIMMIX to account for teamlet-level effects. All analyses were performed using SAS 7.3 (SAS Institute Inc., Cary, NC). Sensitivity analyses were performed to ensure that missing data for some survey items did not affect the overall findings.

\section{Results}

Among 777 PCP-nurse dyads, mean composite task delegation among PCPs was 2.97 (standard deviation [SD], 0.64; range, 1-4) and mean composite task reliance among nurses was 3.26 (SD, 0.50; range, 1-4) (Table 2). Among task subgroups, PCPs reported delegating more for messaging tasks (mean, 3.47) and in-visit data collection (mean, 3.31), and reported delegating less for tracking data (mean, 2.48) and decision making (mean, 2.53). Nurses reported being relied on more than PCPs reported delegating for messaging (mean, 3.66), counseling/education (mean, 3.60), and in-visit data collection (mean, 3.40). The mean (SD) dyadlevel task discordance was 0.91 (0.43) overall, but it was highest for decision making (mean, 1.14; SD, 0.62 ) and tracking data (mean, 1.17; SD, 0.79).

A total of $48 \%$ of PCPs and $35 \%$ of nurses reported burnout (Table 2). Approximately two thirds of respondents reported appropriate staffing (PCPs, 64.3\%; nurses, 66.4\%), and just over half reported recent staff turnover in their clinic (PCPs, $54.4 \%$; nurses, 54.9\%). Mean huddle time was approximately 14 minutes, and about half of respondents reported the presence of a PACT coach. Mean duration of VA employment was just over 8.5 years.

Appropriate staffing was associated with higher composite task delegation for PCPs $(\beta=0.179$; $P<.01)$ but was associated with lower composite task reliance for nurses $(\beta=-0.119 ; P<.01)$ (Table 3). Greater staff turnover was associated with reduced composite task delegation for PCPs ( $\beta=-0.123 ; P=.02)$ but was not associated with composite nurse task reliance. Increased huddle time was associated with higher composite task delegation for both PCPs $(\beta=0.014 ; P<.01)$ and nurses $(\beta=0.006 ; P<.01)$.

Table 4 shows associations of composite task delegation/reliance and other team member and clinic characteristics with burnout. For PCPs, greater composite task delegation was associated with less burnout (odds ratio [OR], 0.62 per unit of composite task delegation; $95 \%$ confidence interval [CI], 0.49-0.78). Among nurses, however, greater composite task reliance was associated with more burnout (OR, 1.83; 95\% CI, 1.33-2.5). In multivariable analysis appropriate staffing was negatively associated with burnout for PCPs and nurses, whereas staff turnover and duration of VA employ- 
Table 2. Perceived Task Delegation/Reliance and Prevalence of Burnout among Veterans Affairs Primary Care Providers and Nurse Care Managers

\begin{tabular}{|c|c|c|c|c|}
\hline & $\begin{array}{c}\text { PCPs } \\
(\mathrm{n}=721)\end{array}$ & $\begin{array}{c}\text { Nurses } \\
(\mathrm{n}=598)\end{array}$ & Difference & $P$ Value \\
\hline Composite task delegation/reliance (15 tasks) & $2.97(0.64)$ & $3.26(0.50)$ & $0.91(0.43)$ & $<.01$ \\
\hline In-visit data collection & $3.31(0.71)$ & $3.40(0.66)$ & $0.80(0.63)$ & $<.01$ \\
\hline Messages & $3.47(0.62)$ & $3.66(0.56)$ & $0.62(0.60)$ & $<.01$ \\
\hline Counseling/education & $3.05(0.82)$ & $3.60(0.53)$ & $0.85(0.68)$ & $<.01$ \\
\hline Decision making & $2.53(0.86)$ & $2.76(0.85)$ & $1.14(0.62)$ & $<.01$ \\
\hline Tracking data & $2.48(1.01)$ & $2.99(0.91)$ & $1.17(0.79)$ & $<.01$ \\
\hline \multicolumn{5}{|l|}{ Burnout } \\
\hline Dichotomized & 48.6 & 34.8 & & $<.01$ \\
\hline \multicolumn{5}{|l|}{ 5-Level categorization } \\
\hline 1 & 13.0 & 23.3 & & \\
\hline 2 & 38.5 & 42.0 & & \\
\hline 3 & 29.0 & 21.5 & & \\
\hline 4 & 12.5 & 8.6 & & \\
\hline 5 & 7.1 & 4.6 & & $<.01$ \\
\hline Appropriate staffing & 64.3 & 66.4 & & .06 \\
\hline Turnover & 54.4 & 54.9 & & .60 \\
\hline Minutes spent in huddles, mean (SD) & $13.30(10.90)$ & $14.33(11.61)$ & & .40 \\
\hline Presence of PACT coach & 45.3 & 50.6 & & .06 \\
\hline Years of VA employment, mean (SD) & $8.53(6.37)$ & $8.61(6.90)$ & & .13 \\
\hline
\end{tabular}

Data are mean (standard deviation) or percentages.

PACT, patient aligned care team; PCP, primary care provider; SD, Standard Deviation; VA, Veterans Affairs.

ment were positively associated with PCP and nurse burnout. Presence of a PACT coach was associated with significantly lower burnout for PCPs only (OR, 0.62; 95\% CI, 0.44-0.86).

Table 4 also shows the associations of task discordance and clinic/respondent characteristics with burnout. Dyad-level task discordance, the difference between perceived PCP task delegation and nurses' reliance, was associated with burnout for PCPs (OR, 1.77; 95\% CI, 1.27-2.47) but not for nurses.

\section{Discussion}

We observed several notable findings in this national cross-sectional study of task delegation and burnout among VA PCP-nurse dyads. First, PCPs reported delegating tasks less than nurses reported being relied on. Second, while increased huddle time was associated with greater task delegation for both PCPs and nurses, appropriate staffing was associated with greater task delegation for PCPs and less perceived task reliance for

Table 3. Multivariable Regression Examining Association of Reported Staffing, Turnover, Huddle Time, Presence of Patient Aligned Care Team Coach, and Length of Veterans Affairs Employment, with a Composite Task Delegation/Reliance Score

\begin{tabular}{lrrrr}
\hline & \multicolumn{2}{c}{ PCPs } & \multicolumn{2}{c}{ Nurses } \\
\cline { 2 - 5 } & \multicolumn{1}{c}{$\beta$} & $P$ Value & $\beta$ & $P$ Value \\
\hline Appropriate staffing & 0.179 & $<.01$ & -0.119 & .01 \\
Staff turnover & -0.123 & .02 & 0.013 & .77 \\
Minutes in huddle & 0.012 & .01 & 0.006 & .01 \\
Presence of PACT coach & -0.005 & .35 & -0.026 & .55 \\
Years at VA & 0.004 & 0.005 & .13 \\
\hline
\end{tabular}

PACT, patient aligned care team; PCP, primary care provider; VA, Veterans Affairs. 
Table 4. Association of Composite Task Delegation/Reliance and Composite Task Discordance, Along with Staffing, Turnover, Huddle Time, Patient Aligned Care Team Coach, and Length of Veterans Affairs Employment, with Workplace Burnout

\begin{tabular}{|c|c|c|c|c|}
\hline & \multicolumn{2}{|c|}{ PCP Burnout } & \multicolumn{2}{|c|}{ Nurse Burnout } \\
\hline & OR & $95 \%$ CI & $\mathrm{OR}$ & $95 \% \mathrm{CI}$ \\
\hline Composite task delegation/reliance (15 tasks) & 0.68 & $0.49-0.93$ & 1.66 & $1.13-2.45$ \\
\hline Appropriate staffing & 0.68 & $0.46-0.99$ & 0.68 & $0.46-1.00$ \\
\hline Staff turnover & 1.74 & $1.20-2.52$ & 1.42 & $0.98-2.07$ \\
\hline Minutes in huddle & 0.98 & $0.96-1.00$ & 1.00 & $0.98-1.02$ \\
\hline Presence of PACT coach & 0.68 & $0.47-0.98$ & 0.83 & $0.57-1.19$ \\
\hline Years at VA & 1.05 & $1.02-1.08$ & 1.00 & $0.97-1.03$ \\
\hline Composite task discordance (15 tasks) & 1.81 & $1.14-2.88$ & 1.26 & $0.84-1.91$ \\
\hline Appropriate staffing & 0.68 & $0.46-0.99$ & 0.65 & $0.44-0.95$ \\
\hline Turnover & 1.83 & $1.27-2.65$ & 1.42 & $0.98-2.06$ \\
\hline Huddle time & 0.98 & $0.96-0.99$ & 1.00 & $0.99-1.02$ \\
\hline PACT coach present & 0.68 & $0.47-0.98$ & 0.83 & $0.58-1.19$ \\
\hline Years at VA & 1.05 & $1.02-1.08$ & 1.00 & $0.98-1.03$ \\
\hline
\end{tabular}

CI, confidence interval; OR, odds ratio; PACT, patient aligned care team; PCP, primary care provider; VA, Veterans Affairs.

nurses. Finally, increased delegation of tasks was associated with lower burnout for PCPs, but increased task reliance reported by nurses was associated with increased burnout. Dyad-level task discordance was associated with burnout for PCPs only.

The ongoing workforce shortage in primary care has led to urgent calls to make the practice of primary care more rewarding for clinicians, with the hope that this will increase the number of trainees who choose careers in primary care and retain PCPs currently in practice. ${ }^{36}$ One oftencited means to improve the worklife of PCPs is sharing the workload by having them delegate routine tasks to other team members, thereby allowing them to focus on clinical care of patients. This study demonstrates that PCPs who report more frequent delegation of tasks to their primary care staff do indeed report less burnout. This is an encouraging finding, suggesting that efforts to improve task delegation may improve work life for PCPs.

However, nurses who perceived a high level of reliance for tasks also reported more burnout. This suggests that nurses may perceive task delegation as simply increasing their workload, which is a key contributor to burnout. ${ }^{17}$ Because nurses have a broad scope of practice, they can perform a wide range of tasks. When PCPs are unsure of which team member should be doing a given task, delegating to a nurse may become a default. This issue could be exacerbated by inadequate staffing at the administrative associate levels. Such inefficient delegation is consistent with our findings: We observed that, among nurses, perceived task reliance was higher in teams that were not fully staffed, suggesting that tasks cannot be delegated to other team members.

Task discordance, the dyad-level difference in perceptions of task delegation between PCPs and nurses, was associated with burnout for PCPs but not for nurses. Task discordance could reflect a communication problem that is more frustrating for PCPs. Alternatively, as nurses report high levels of task reliance for all tasks, ${ }^{11}$ this discordance could be driven by PCP responses and as such is more reflective of PCPs' levels of task delegation.

Ideally, with training, coaching, and team huddles, the appropriate roles of each team member are individually negotiated and agreed upon, so that tasks are delegated appropriately, minimizing overload on any 1 team member. It is encouraging to note that increased huddle time was associated with increased task delegation for both PCPs and nurses. In addition, among PCPs, the presence of a PACT coach was associated with increased task delegation, suggesting that practice facilitation has an important role in assisting teams to appropriately assign work among team members.

Inadequate staffing and recent staff turnover were strongly associated with burnout for both 
PCPs and nurses, as has been shown previously. ${ }^{26}$ Developing functional team relationships that allow for effective team-based task delegation requires a fully staffed PACT team and adequate time spent working together to learn how to maximize each team member's skill set. Without well-staffed, trained, and stable teams, the complex job of efficiently sharing work among a primary care teamlet may be impossible.

A particular challenge in sharing work across a primary care team is that many essential primary care tasks may be perceived as unrewarding and contributing to burnout. For example, requesting outside records, sending patients normal laboratory test results or calling in updated home health orders can feel like rote busywork, even though such tasks are important in providing coordinated care. Because PCPs often want to delegate these tasks, it is important to ensure that delegation does not exacerbate burnout for other team members. As described above, 1 solution is to make sure that teams are adequately staffed to prevent nurses from being asked to perform tasks that other team members are qualified to do. Another avenue is to make sure that all team members share in meaningful, rewarding work with transparent results. ${ }^{29}$ For example, developing longitudinal relationships with patients can greatly increase providers' sense of purpose in their jobs, ${ }^{37}$ and this role could be shared across the team. Clinic leadership could also stress the critical contributions of all team members and the importance of all team members' work to patient health.

This study has several limitations. First, we relied on a single-item measure of burnout, whereas the Maslach Burnout Inventory separately measures the 3 dimensions of burnout: emotional exhaustion, lack of enthusiasm, and feelings of ineffectiveness. However, this single-item measure has been used previously ${ }^{38}$ and shows strong correlation with the emotional exhaustion subscale of the Maslach Burnout Inventory. ${ }^{33}$ Second, as a crosssectional survey, we cannot make conclusions regarding causation, only association. With subsequent surveys of VA PCPs and staff, we may be able to study how changes in task delegation affect burnout over time. Unfortunately, the current survey was anonymous, which prevents the tracking of individual respondents. Third, the survey had a low individual response rate, risking that the sample is not representative of all VA primary care clinicians and staff. Nevertheless, our sample of 777 PCP-nurse dyads represents a large sample of PCPs and nurses who work together directly, in which perceptions of work responsibility can be directly compared. Fourth, we only examined perceptions of PCPs and nurses, although PACT teams also include other roles, and delegation can occur among all team members. Finally, although the tasks we chose are commonly performed by primary care teams, our list is not comprehensive.

\section{Conclusion}

We demonstrate that in PCP-nurse dyads from teamlets, perceived task delegation is associated with less reported burnout for PCPs but more burnout for nurses, suggesting that efforts to reduce burnout among PCPs by delegating work to nurses may inadvertently increase burnout among those nurses. Guidelines for task delegation within a teamlet should be developed to reduce the likelihood of burnout among nurses.

To see this article online, please go to: bttp://jabfm.org/content/ 31/1/83. full.

\section{References}

1. Hysong SJ, Best RG, Moore FI. Are we underutilizing the talents of primary care personnel? A job analytic examination. Implement Sci 2007;2(1):10.

2. Wetterneck TB, Lapin JA, Krueger DJ, Holman GT, Beasley JW, Karsh B-T. Development of a primary care physician task list to evaluate clinic visit workflow. BMJ Qual Saf 2012;21:47-53.

3. Holman GT, Beasley JW, Karsh BT, Stone JA, Smith PD, Wetterneck TB. The myth of standardized workflow in primary care. J Am Med Inform Assoc 2016;23:29-37.

4. Stange KC, Zyzanski SJ, Jaen CR, et al. Illuminating the "black box". A description of 4454 patient visits to 138 family physicians. Fam Pract 1998;46: 377-89.

5. Altschuler J, Margolius D, Bodenheimer T, Grumbach K. Estimating a reasonable patient panel size for primary care physicians with team-based task delegation. Ann Fam Med 2012;10:396-400.

6. Green LV, Savin S, Lu Y. Primary care physician shortages could be eliminated through use of teams, nonphysicians, and electronic communication. Health Aff (Millwood) 2013;32:11-9.

7. Bowling A. Delegation to nurses in general practice. J R Coll Gen Pract 1981;31:485-90.

8. Bosley S, Dale J. Healthcare assistants in general practice: practical and conceptual issues of skill-mix change. Br J Gen Pract 2008;58:118-24. 
9. Giannitrapani KF, Soban L, Hamilton AB, et al. Role expansion on interprofessional primary care teams: barriers of role self-efficacy among clinical associates. Healthc (Amst) 2016;4:321-6.

10. True G, Stewart GL, Lampman M, Pelak M, Solimeo SL. Teamwork and delegation in medical homes: primary care staff perspectives in the Veterans Health Administration. J Gen Intern Med 2014; 29(Suppl 2):S632-9.

11. Edwards ST, Rubenstein LV, Meredith LS, et al. Who is responsible for what tasks within primary care: perceived task allocation among primary care providers and interdisciplinary team members. Healthc (Amst) 2015;3:142-9.

12. Aita V, Dodendorf DM, Lebsack JA, Tallia AF, Crabtree BF. Patient care staffing patterns and roles in community-based family practices. Fam Pract 2001;50:889.

13. Grace SM, Rich J, Chin W, Rodriguez HP. Implementing interdisciplinary teams does not necessarily improve primary care practice climate. Am J Med Qual 2016;31:5-11.

14. Dini L, Sarganas G, Boostrom E, Ogawa S, Heintze C, Braun V. German GPs' willingness to expand roles of physician assistants: a regional survey of perceptions and informal practices influencing uptake of health reforms in primary health care. Fam Pract 2012;29:448-54.

15. Rodriguez HP, Giannitrapani KF, Stockdale S, Hamilton AB, Yano EM, Rubenstein LV. Teamlet structure and early experiences of medical home implementation for veterans. J Gen Intern Med 2014; 29(Suppl 2):S623-31.

16. Aiken LH, Clarke SP, Sloane DM, Sochalski J, Silber JH. Hospital nurse staffing and patient mortality, nurse burnout, and job dissatisfaction. JAMA 2002; 288:1987-93.

17. Maslach C, Jackson SE. The measurement of experienced. J Occup Behav 1981;2:99-113.

18. Shanafelt TD, Boone S, Tan L, et al. Burnout and satisfaction with work-life balance among US physicians relative to the general US population. Arch Intern Med 2012;172:1377-85.

19. Puffer JC, Knight C, O’Neill TR, et al. Prevalence of burnout in board certified family physicians. J Am Board Fam Med 2017;30:125-6.

20. McHugh MD, Kutney-Lee A, Cimiotti JP, Sloane DM, Aiken LH. Nurses's widespread job dissatisfaction, burnout, and frustration with health benefits signal problems for patient care. Health Aff (Millwood) 2011;30:202-10.

21. Haas JS, Cook EF, Puopolo AL, Burstin HR, Cleary $\mathrm{PD}$, Brennan TA. Is the professional satisfaction of general internists associated with patient satisfaction? J Gen Intern Med 2000;15:122-8.

22. Halbesleben JR, Rathert C. Linking physician burnout and patient outcomes: exploring the dyadic rela- tionship between physicians and patients. Health Care Manage Rev 2008;33:29-39.

23. Spence Laschinger HK, Leiter MP. The impact of nursing work environments on patient safety outcomes: the mediating role of burnout/engagement. J Nurs Adm 2006;36:259-67.

24. West CP, Huschka MM, Novotny PJ, et al. Association of perceived medical errors with resident distress and empathy: a prospective longitudinal study. JAMA 2006;296:1071-8.

25. Landon BE, Reschovsky JD, Pham HH, Blumenthal D. Leaving medicine: the consequences of physician dissatisfaction. Med Care 2006;44:234-42.

26. Helfrich CD, Simonetti JA, Clinton WL, et al. The association of team-specific workload and staffing with odds of burnout among VA primary care team members. J Gen Intern Med 2017;32:760-6.

27. Ladebue AC, Helfrich CD, Gerdes ZT, Fihn SD, Nelson KM, Sayre GG. The experience of Patient Aligned Care Team (PACT) members. Health Care Manage Rev 2016;41:2-10.

28. Willard-Grace R, Hessler D, Rogers E, Dube K, Bodenheimer T, Grumbach K. Team structure and culture are associated with lower burnout in primary care. J Am Board Fam Med 2014;27:229-38.

29. Sinsky CA, Willard-Grace R, Schutzbank AM, Sinsky TA, Margolius D, Bodenheimer T. In search of joy in practice: a report of 23 highfunctioning primary care practices. Ann Fam Med 2013;11:272-8.

30. Department of Veterans Affairs. Analyzing tasks for the patient centered medical home. Available from: http://www.va.gov/HEALTH/services/primarycare/pact/resources.asp. Accessed November $15,2017$.

31. Helfrich CD, Dolan ED, Simonetti J, et al. Elements of team-based care in a patient-centered medical home are associated with lower burnout among VA primary care employees. J Gen Intern Med 2014; 29(Suppl 2):659-66.

32. Nelson KM, Helfrich C, Sun H, et al. Implementation of the patient-centered medical home in the Veterans Health Administration: associations with patient satisfaction, quality of care, staff burnout, and hospital and emergency department use. JAMA Intern Med 2014;174:1350-8.

33. Dolan ED, Mohr D, Lempa M, et al. Using a single item to measure burnout in primary care staff: a psychometric evaluation. J Gen Intern Med 2015;30:582-7.

34. Williams ES, Konrad TR, Linzer M, et al. Physician, practice, and patient characteristics related to primary care physician physical and mental health: results from the Physician Worklife Study. Health Serv Res 2002;37:121-43.

35. Rohland BM, Kruse GR, Rohrer JE. Validation of a single-item measure of burnout against the Maslach Burnout Inventory among physicians. Stress Health 2004;20:75-9. 
36. Bodenheimer T, Sinsky C. From triple to quadruple aim: care of the patient requires care of the provider. Ann Fam Med 2014;12:573-6.

37. Beach MC, Inui T; Relationship-Centered Care Research Network. Relationship-centered care. A constructive reframing. J Gen Intern Med 2006; 21(Suppl 1):S3-8.

38. Linzer M, Manwell LB, Williams ES, et al. Working conditions in primary care: physician reactions and care quality. Ann Intern Med 2009;151:28-36, W6-9. 
Appendix Table 1. Perceived Delegation and Reliance of Individual Tasks for Primary Care Physicians and Nurses

\begin{tabular}{|c|c|c|c|}
\hline & $\begin{array}{c}\text { PCPs } \\
(\mathrm{n}=721)\end{array}$ & $\begin{array}{l}\text { Nurses } \\
(\mathrm{n}=598)\end{array}$ & $P$ Value \\
\hline $\begin{array}{l}\text { Gathering patient preventive services utilization history (eg, } \\
\text { immunization history) }\end{array}$ & $3.33(0.92)$ & $3.30(0.89)$ & .73 \\
\hline Screening patients for diseases (eg, doing a depression screen) & $3.35(0.90)$ & $3.30(0.91)$ & .85 \\
\hline Assessing patient lifestyle factors & $3.25(0.84)$ & $3.60(0.65)$ & $<.01$ \\
\hline Receiving messages from patients & $3.70(0.60)$ & $3.75(0.58)$ & .08 \\
\hline $\begin{array}{l}\text { Resolving messages from patients (other than requests for } \\
\text { prescriptions) }\end{array}$ & $3.49(0.73)$ & $3.72(0.62)$ & $<.01$ \\
\hline Responding to prescription refill requests & $3.06(1.04)$ & $3.51(0.75)$ & $<.01$ \\
\hline Encouraging lifestyle modifications & $3.17(0.88)$ & $3.70(0.56)$ & $<.01$ \\
\hline $\begin{array}{l}\text { Educating patients about disease-specific self-care activities } \\
\text { (eg, foot care in diabetes) }\end{array}$ & $3.11(0.94)$ & $3.63(0.65)$ & $<.01$ \\
\hline Educating patients about medications & $2.87(0.97)$ & $3.47(0.76)$ & $<.01$ \\
\hline Evaluating patients and making treatment decisions & $2.64(1.02)$ & $2.91(1.10)$ & $<.01$ \\
\hline Completing forms for patients & $2.20(1.11)$ & $2.41(1.11)$ & $<.01$ \\
\hline Responding to requests for home health care orders & $2.67(1.12)$ & $2.69(1.14)$ & 0.40 \\
\hline $\begin{array}{l}\text { Responding to patient diagnostic and treatment data (eg, } \\
\text { laboratory tests, radiology studies) }\end{array}$ & $2.58(1.10)$ & $3.00(1.03)$ & $<.01$ \\
\hline Following-up on referrals (eg, to specialists) & $2.49(1.09)$ & $2.95(1.02)$ & $<.01$ \\
\hline
\end{tabular}

PCPs, primary care providers. 


\begin{tabular}{|c|c|c|}
\hline & PCP Burnout & Nurse Burnout \\
\hline In-visit data collection & $0.90(0.66-1.21)$ & $1.09(0.83-1.44)$ \\
\hline $\begin{array}{l}\text { Gathering patient preventive services utilization } \\
\text { history (eg, immunization history) }\end{array}$ & $1.02(0.81-1.28)$ & $0.88(0.72-1.08)$ \\
\hline $\begin{array}{l}\text { Screening patients for diseases (eg, doing a } \\
\text { depression screen) }\end{array}$ & $1.04(0.83-1.31)$ & $0.92(0.75-1.12)$ \\
\hline Assessing patient lifestyle factors & $0.76(0.59-0.96)$ & $1.02(0.77-1.35)$ \\
\hline Messages & $0.75(0.54-1.04)$ & $0.95(0.68-1.32)$ \\
\hline Responding to prescription refill requests & $0.75(0.62-0.91)$ & $1.39(1.07-1.80)$ \\
\hline Receiving messages from patients & $0.93(0.67-1.29)$ & $1.46(1.00-2.13)$ \\
\hline $\begin{array}{l}\text { Resolving messages from patients (other than } \\
\text { requests for prescriptions) }\end{array}$ & $1.05(0.79-1.39)$ & $1.38(0.99-1.93)$ \\
\hline Counseling/education & $0.70(0.55-0.90)$ & $0.94(0.66-1.33)$ \\
\hline Encouraging lifestyle modifications & $0.77(0.61-0.97)$ & $1.04(0.76-1.43)$ \\
\hline $\begin{array}{l}\text { Educating patients about disease-specific self-care } \\
\text { activities (eg, foot care in diabetes) }\end{array}$ & $0.82(0.67-1.02)$ & $0.82(0.62-1.09)$ \\
\hline Educating patients about medications & $0.73(0.60-0.90)$ & $1.34(1.03-1.75)$ \\
\hline Decision making & $0.77(0.61-0.96)$ & $0.91(0.73-1.13)$ \\
\hline Evaluating patients and making treatment decisions & $0.81(0.68-0.97)$ & $1.27(1.06-1.51)$ \\
\hline Completing forms for patients & $0.86(0.73-1.01)$ & $1.21(1.03-1.43)$ \\
\hline Responding to requests for home health care orders & $0.94(0.79-1.11)$ & $1.24(1.05-1.47)$ \\
\hline $\begin{array}{l}\text { Responding to patient diagnostic and treatment } \\
\text { data (eg, laboratory tests, radiology studies) }\end{array}$ & $0.81(0.68-0.96)$ & $1.20(1.00-1.44)$ \\
\hline Tracking data & $0.88(0.73-1.06)$ & $0.94(0.76-1.15)$ \\
\hline Tracking patient diagnostic data & $0.87(0.73-1.03)$ & $1.14(0.95-1.37)$ \\
\hline Following up on referrals (eg, to specialists) & $0.95(0.80-1.13)$ & $1.45(1.20-1.76)$ \\
\hline
\end{tabular}

Data are adjusted odds ratios (95\% confidence intervals).

${ }^{*}$ Model also includes appropriate staffing, recent turnover, presence of Patient Aligned Care Team coach, and duration of Veterans Affairs employment.

PCPs, primary care providers. 